\title{
UNDERSTANDING THE CONTRIBUTION AND CHALLENGES OF USING SOFT SYSTEMS METHODOLOGY TO FACILITATE CULTURAL CHANGE: A CASE STUDY IN THE PUBLIC SECTOR.
}

\begin{abstract}
Collaboration between professional agencies in the public sector is essential to provide seamless, high quality services to citizens. Inter-agency working is often hindered by a prevalent silo culture, reinforced by resource-focused funding mechanisms. Checkland's Soft Systems Methodology (SSM) aims to facilitate organizational improvement or change through an organizational learning approach. In this study, SSM was used to help facilitate a move towards partnership working in the public sector. Interview data was collected from senior members of 16 professional agencies, four months after completing the SSM activity to reflect on the experience. The interviews were then repeated 12 months later in order to facilitate reflection on the use, role and impact of SSM beyond any immediate effect. From the interviews, we identified contributions of change that were attributed to the use of SSM and challenges of using SSM to facilitate cultural change. The challenges are explored in four themes: the process of stakeholder selection; the power of stakeholders; the ensuing power structure within the problem situation; the role of SSM and systemic change. These themes are discussed as contributing factors that practitioners of SSM need to be aware of to ensure the sanctity of SSM during periods of cultural change.
\end{abstract}

Keywords: Soft Systems Methodology, Case Study, Cultural Change, Public Sector 


\section{Introduction}

The Soft Systems Methodology (SSM) is one of the most well-known of a group of alternative information system methodologies which have been designed to account for and integrate the human and social factors of organizations while information systems are being designed (Checkland 1981; Checkland and Scholes, 1999; Wilson, 1990, 2001). The contribution of SSM to structural, process, or attitudinal change has been claimed by Checkland and Scholes (1999) to be one of its most powerful characteristics. SSM offers a systemic framework which can be used to explore problem situations and result in some kind of change or improvement. Documented examples of the application of SSM exist (for example, Kalim et al., 2004; Jacobs, 2004; Kotiadis, 2007; Torlak and Müceldili, 2014) however there has been little attempt to evaluate the effectiveness of SSM in the process of change (for example, Connell, 2001). There is also a need for research focusing on the 'outcomes and successes of change in public organizations' (Kuipers et al., 2014).

The case study reported here is part of a wider research project that aims to examine the effectiveness of SSM to contribute to systemic change processes within public sector environments in the UK. SSM was applied in a local metropolitan borough council (MBC) to progress the design and implementation of an information management and technology (IM\&T) strategy during a period of significant organizational change. Interviews with stakeholders were conducted four months after the SSM activity and repeated 12 months later. From these interviews we identified contributions of change attributed to the use of SSM and challenges of using SSM to facilitate cultural change. The challenges are categorized into contextual factors influencing the SSM activity and factors inhibiting organizational change. The challenges are further explored in four themes: the process of stakeholder selection; the power of stakeholders; the ensuing power structure within the problem situation; the role of SSM and systemic change. We discuss these themes and raise awareness of the contextual factors that practitioners of SSM need to be aware of when applying SSM in powerful organizational cultures.

The following section briefly explores previous literature on SSM and the role of partnership working in the public sector. The case study that provides the context for this research is then introduced and the research process is described. The findings from analysis of interview data are presented in sections 5 and 6 , and discussed in section 7 . The paper concludes by discussing the relevance of the findings to SSM practitioners and reviews the limitations and future direction of the research.

\section{Background}

\subsection{Soft Systems Methodology}

SSM was initially developed to provide a structured methodology which could be used to carry out organizational analysis within what were seen as problematic environments. Two broad approaches to SSM have been developed. Checkland's interpretation advocates SSM as an organizational learning process with the aim of achieving organizational improvement or change. This approach accords considerable significance to the sociology, politics and culture of a situation during the process of organizational analysis as these factors are considered to play an important role in the process of change (Checkland \& Scholes, 1999). The second approach, associated with Wilson (1990), is more specifically focused on the field of information systems development. Wilson's interpretation likewise places a strong emphasis on socio-cultural analysis, but the ultimate aim of using this approach is to produce information systems requirements sensitized to an organizational context. The systemic interpretation of social and cultural factors is deemed to be important in interpreting that context, but they are not 
accorded the strong causal status to be found in Checkland's work. The process of SSM involves the collection of each stakeholder's worldview, which is then used to create a systems model (a human activity system). Checkland's SSM comprises the following stages: i) unstructured problem situation, ii) problem situation expressed, iii) root definitions of relevant systems, iv) conceptual models, v) comparison of conceptual models with expression of problem situation, vi) identify feasible, desirable changes, vii) action to improve problem situation. Although Checkland's approach is examined and utilized in what follows, consensus modelling from Wilson's approach has also been used to help move towards an agreed system of change.

\subsection{Partnership in the Public Sector}

The pressure for local authorities and health service environments to collaborate and join together in partnership was initially driven by funding arrangements. "Partnership is no longer simply an option; it is a requirement" (Dowling et al., 2004:309). There is however, no generally agreed definition of partnership; the term could apply to either the form or type of organization, or to a way of working. The ambiguity over structures versus process is compounded by confusion regarding the aims of partnerships. Knight and Harland (2005) draw the distinction in problem focus between strategic issues and logistical or operational problems.

Open government requires transparency and participation within a culture of open communication and sharing of knowledge, which requires a fundamental cultural change (Ruijer and Huff, 2016). The paradigm shift towards partnership working in the public sector is problematic. Partnership breaks down bureaucratic certainties and addresses realities which are complex and fragmented (Wastell et al., 2004). Integrated information systems are needed to facilitate collaborative working in the public sector (Signoretta and Craglia, 2002) and support ambitions of open government. Lee and Kwak (2012) outline five stages of open government maturity from the initial provision of a static public web page, through increased data transparency, open participation and open collaboration, to attain ubiquitous engagement demonstrated by seamless integration of public services accessible across mobile and computing platforms. A key challenge of moving from the initial conditions of stage one is the hierarchical culture of government and agency silos (Lee and Kwak, 2012). The "main barriers to data exchange are cultural rather than technical or legislative" (Wastell et al., 2004:203); trust is a prerequisite for both a successful partnership and an underpinning strategy of data and information exchange.

\section{Case Study: The Unstructured Problem Situation}

This case study is situated in a metropolitan borough council (MBC) in the UK with a population of approximately 316,720, comprising of a diverse ethnic mix. A Civic Partnership was formed made up of the major agencies of voluntary organizations, health, local authorities, police authorities, Chamber of Commerce, and local industries, in order to address the challenge of social deprivation in the area. The environment of the MBC was characterized by a myriad of different projects and initiatives as a consequence of separate and independent funding streams. The founding of the Partnership was influenced by the realization that larger projects could not be delivered solely by one agency. There was a desire to bring about change on a Borough-wide level and to underpin this change with joined-up services, creating new institutional forms based on inter-agency models of working.

A Partnership Information group was established, representing all the major service providers within the borough to define an Information Management and Technology (IM\&T) strategy to support data exchange between professional agencies and to provide seamless delivery of services to citizens. The creation of an integrated information and communication strategy for the MBC was complicated by the idiosyncratic information requirements and data protocols of the various agencies and service providers. The NHS in the UK, for example, has been subject to significant change (Kelliher and Parry, 2015). This presented a particular challenge to the creation of an integrated IM\&T strategy because of 
incompatible legacy systems and issues of data protection relating to patient data and to the transference of information across agencies (between, for example, the health and police authorities). The motives for sharing data and information, and the use to which that information could be put, was not consistent across the Partnership.

The response to these issues was to attain agreement on a number of streams and principles for the strategy. An overall vision of what the IM\&T strategy would mean to all the agencies and stakeholders was lacking and the formulation of the strategy stalled. This appeared to be because the agencies of the Partnership had become absorbed with their own localized information management issues and were not addressing how they could be resolved holistically, or at the level of the Partnership as a whole. A member of the Partnership was aware of SSM and believed it could be applied to this problem situation because it was an approach that enables problems to be explored at a systemic level.

\section{$4 \quad$ Methodology}

SSM is usually practised in either Mode One or Mode Two. In Mode One all the stages are generally followed sequentially (Checkland \& Holwell, 1998). In Mode Two users of the methodology tailor the use of the methodology to each situation, using the principles of the methodology as a sense-making device. In this case Mode Two was used to represent a practical example of interpretive systems which can be applied to client-led design (Stowell, 1995). The problems are expressed through the model building, but the principles of systems thinking as supported by SSM are used to navigate a more flexible mode of enquiry. Table 1 presents an overview of the approach taken.

\begin{tabular}{|c|c|c|}
\hline \multirow{2}{*}{ 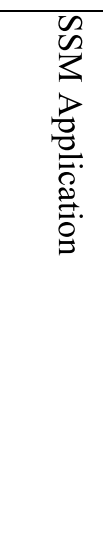 } & \multicolumn{2}{|c|}{ Phase 0: The Unstructured Problem Situation (Checkland Stage 1) } \\
\hline & $\begin{array}{l}\text { Phase 1: Expressing the Problem Situation } \\
\text { (Checkland Stages 2, } 3 \text { and 4): } \\
\text { - Initial meeting to identify stakeholders. } \\
\text { - Individual meetings with } 16 \text { stakeholders to } \\
\text { introduce SSM and derive worldviews. } \\
\text { - Formation of root definitions of relevant } \\
\text { systems. } \\
\text { - Development of a conceptual model from } \\
\text { each stakeholder interview. }\end{array}$ & $\begin{array}{l}\text { Phase 2: SSM Modelling Workshop (Checkland } \\
\text { Stages 4, } 5 \text { and 6; Wilson Consensus } \\
\text { Modelling): } \\
\text { - Group discussion of conceptual models. } \\
\text { - } \quad \text { Development of consensus models. } \\
\text { - } \quad \text { Agreement on action to be taken. }\end{array}$ \\
\hline 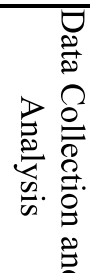 & $\begin{array}{l}\text { Phase 3: Post SSM Application Evaluation (4 } \\
\text { Months Later): } \\
\text { - Individual semi-structured interviews with } \\
\text { stakeholders. } \\
\text { - Transcription and coding of interviews. }\end{array}$ & $\begin{array}{l}\text { Phase 4: Post SSM Application Evaluation (12 } \\
\text { Months Later): } \\
\text { - Individual semi-structured interviews with } \\
\text { stakeholders. } \\
\text { - Transcription and coding of interviews. }\end{array}$ \\
\hline & \multicolumn{2}{|c|}{ Phase 5: Analysis of Findings } \\
\hline
\end{tabular}

Table 1. Overview of Research Approach

The application of SSM in the MBC (phases 1-2) was concentrated over two months due to institutional circumstances. A sense of urgency had arisen from previously unsuccessful attempts to move the IM\&T strategy forward, resulting in a desire to focus the application into a contracted timescale, thus endowing it with tangible momentum. 
Semi-structured assessment interviews were conducted to evaluate the impact of SSM in the change process, as perceived by the stakeholders within four months and then again 12 months following the commencement of the study. The longitudinal view was intended to facilitate an assessment of the impact of SSM beyond any immediate, tangible effect, in an attempt to surface deeper impacts, such as changes to organizational culture and modus operandi. Sixteen stakeholders took part in the SSM application and the first assessment interviews; as a result of changing roles and staff turnover, twelve stakeholders took part in the second set of assessment interviews. The impact of personnel turnover must be acknowledged during consideration of longitudinal data. Furthermore, any analysis of a longitudinal view of the impact of SSM must take into account the likely influence of other organizational events and changes in the problem situation (which may or may not have been prompted by SSM).

\subsection{Participants' engagement with SSM}

The facilitator had been approached by a member of the Partnership who was familiar with SSM, and was invited to an initial meeting with senior members of the Partnership to discuss the approach and how it could be applied. Written materials explaining the approach were widely circulated, and time was allocated to explain the approach in more detail during one-to-one meetings with stakeholders, prior to the collection of worldviews. Following each worldview interview, a conceptual model was constructed and both facilitator and stakeholder worked through the model to ensure stakeholder ownership and deepen understanding. This process helped participants to understand the approach in more depth, particularly the systemic aspects of SSM, which enabled them to actively engage with the consensus workshops. Throughout the application, the facilitator collected observer's notes relating to both how the participants engaged with SSM and the degree to which the approach became embedded as a modus operandi for the organisation. These observations are briefly reported in the conclusion.

\subsection{Phase 1: Expressing the Problem Situation}

A number of initial visits were made to the MBC to discuss the application of SSM and to gather some information about the organization, the IM\&T strategy work to date and the problem situation. The client organization required the modelling work to be completed within a 15 day period. This urgency was driven by the need to address a problem which had already been stagnating for some time. It also meant that assimilation of the methodology by the stakeholders and the preparation of the models had to be done in a very focussed and intense way.

The application of SSM to the problem situation began by identifying 16 stakeholders in the development of the IM\&T strategy for the MBC, including senior representatives from the council, local health authority, education services, police and voluntary sectors. Initial meetings between the facilitator and each stakeholder were arranged. Written material about SSM was circulated to each stakeholder in advance of the meeting and discussed in detail during the initial meeting. The main purpose of the meeting was to gain the stakeholder's worldview and this was elicited through the question: What is your view of a borough-wide IM\&T strategy?

Three themes emerged from these initial meetings, which provided preliminary insight into the reasons behind the deadlock on the IM\&T strategy: the need for seamless joined up services; different views regarding the overarching Partnership strategy; and the relative importance of the technical agenda. Following each meeting, a CATWOE (customer/actor/transformation process/worldview/owner sequence) and a conceptual model was drawn up for each of the stakeholders, based on their worldview.

\subsection{Phase 2: Soft Systems Modelling}

When the modelling of the worldviews had been completed, a workshop was held to debate the resulting models with stakeholders, facilitated by one of the authors. The aim of the workshop was to attempt to reach an accommodation of worldviews and construct one or more conceptual models which would help 
to drive the strategy forward. Two key themes emerged from the process of examining and debating the conceptual models:

- A need to reconcile a funding/budget driven culture within the Partnership with the need for a cohesive strategic agenda. This was identified as a Partnership issue.

- The requirement for a supporting infrastructure of information and knowledge management across the Partnership. This was identified as an information strategy issue.

In response to this, stakeholders initially agreed that a hierarchy of three systems needed to be considered: the need to create change within the Partnership; the adequacy of mechanisms for information management; and the technical infrastructure required to deliver any IM\&T strategy. CATWOES and conceptual models were developed, which were used to produce a business case for the appointment of a new post of Executive Director to lead the IM\&T strategy. The stakeholders perceived this to be a considerable step forward and at this point, the SSM application process formally ended.

\subsection{Data Collection and Analysis}

Semi-structured interviews with stakeholders were held four months after the SSM workshop. The purpose of the interviews was to obtain each individual's view of the effectiveness of the application with regard to achieving an IM\&T strategy for the Partnership and to reflect on the role of SSM in the change process. The interviews were repeated 12 months after the SSM application to obtain a longitudinal view of the effectiveness of the application and its role with regard to the achievement of an IM\&T strategy. The interview data were analysed qualitatively using template analysis (Crabtree and Miller, 1999) and a basic form of grounded theory (open coding) (Strauss and Corbin, 1998). King (1998) positions this approach between content analysis (Weber, 1995), where codes are determined $a$ priori and are statistically analysed, and the grounded theory approach of Glaser and Strauss (1967) in which codes are not pre-determined. Template analysis therefore occupies a middle ground and enables researchers to adopt a flexible and less prescribed approach to analysis, reflecting the "differing philosophical orientations of researchers" (King, 1998:118). It was recognized that this flexibility needed to accommodate the recognition of both a priori codes and codes which are not pre-determined; essentially this is a social constructionist view of analysis which was considered appropriate to an evaluation of SSM.

Themes yielded by the raw data of the interview transcripts were separated between those that were directly related to the application of SSM and those relating to the wider context in which the study took place. They are shown in Table 2 and discussed in the following sections. Factors influencing the SSM application were not discussed in the second interviews due to the time span since the workshop.

\begin{tabular}{|l|l|}
\hline Post SSM Application Evaluation (4 Months) & Post SSM Application Evaluation (12 Months) \\
\hline $\begin{array}{l}\text { Contribution of SSM Activity to Organizational } \\
\text { Change Process: }\end{array}$ & $\begin{array}{l}\text { Contribution of SSM Activity to Organizational } \\
\text { Change Process: }\end{array}$ \\
- Created organizational insight. & $\begin{array}{l}\text { Gave confidence to act. } \\
\text { - Empowered stakeholders. }\end{array}$ \\
- Created clarity and legitimacy. & - Cacilitated move towards partnership culture. \\
- Defined agreed direction for action. & \\
\hline
\end{tabular}




\begin{tabular}{|c|c|}
\hline $\begin{array}{l}\text { Contextual Factors Inhibiting Organizational Change } \\
\text { Process: } \\
\text { - Persistent silo culture. } \\
\text { - } \quad \text { Espoused partnership culture. } \\
\text { - Tenacious political culture. } \\
\text { - Organizational history. } \\
\text { - Strategic events. } \\
\text { - Different priorities. } \\
\text { - Lack of momentum. }\end{array}$ & $\begin{array}{l}\text { Contextual Factors Inhibiting Organizational Change } \\
\text { Process: } \\
\text { - Persistent silo culture. } \\
\text { - } \quad \text { Espoused partnership culture. } \\
\text { - } \quad \text { Tenacious political culture. } \\
\text { - Strategic events. } \\
\text { - } \quad \text { Different priorities. } \\
\text { - Lack of momentum. } ~ \text { Lack of ownership. } \bigcirc \\
\quad \text { Lack of resources. } \\
\text { o Changes in personnel. } \odot \text { Lack of alignment } \\
\text { of strategy and processes. }\end{array}$ \\
\hline 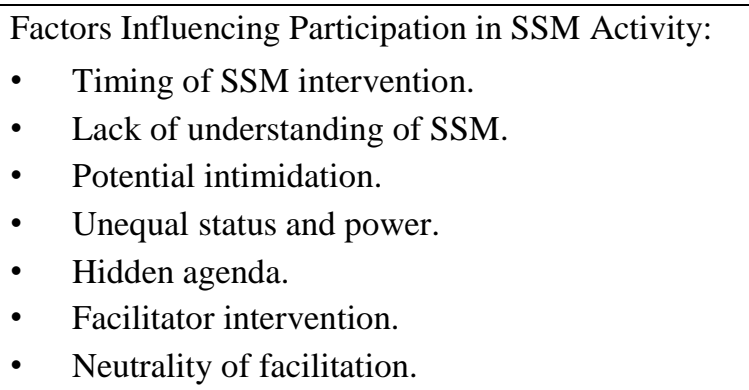 & \\
\hline
\end{tabular}

Table 2. Contributions and Challenges of Using SSM

\section{$5 \quad$ Phase 3: Post SSM Application Evaluation (4 Months)}

\subsection{Contributions of SSM Activity to Organizational Change Process}

The interviews revealed that the use of SSM had led to tangible outcomes regarding organizational activity and appeared to have influenced to some degree the way that stakeholders thought and behaved. These areas are clearly interconnected (since, for example, a change of behaviour may lead to an organizational event taking place). It was also clear that the stakeholders could be divided into two groups:

A) those who were at the centre of and strategically connected to the Partnership, 'insiders' who perceived that the analysis had had some impact on the problem situation,

B) and 'outsiders' who were on the periphery of Partnership activity and who were largely of the opinion that no real change had occurred as a result of using SSM.

Analysis of the interview transcripts does not indicate that the application of SSM produced any substantial impact on this divide; indeed, it may even have exacerbated it. The following contributions of SSM emerged from the interview data.

Created Organizational Insight: The bureaucracy of the public sector had led to meetings where the "agenda is fairly rigid". This has led to "some very simplistic thinking" about the Partnership. SSM provided a creative space to explore the "quite major differences between partners" and "identify the complexity" of the situation.

Gave Confidence to Act: In relation to the IM\&T strategy, "a piece of learning went on which... gave people confidence to shift from...thinking about solutions without ever doing anything about it to being willing to share those ideas...take risks... and then act on them [the ideas]." 
Empowered Stakeholders: Stakeholder 7 believed that the SSM application "brought people together to get a view of where they were, of where they wanted to go." This was reflected by Stakeholder 3, "I've certainly seen a change...before, we were being very analytical and systematic and breaking it down and were actually going completely down the wrong path."

Created Clarity and Legitimacy: SSM "helped crystallize things at a critical moment." The process provided "an independent view... which underlined a particular perspective that in effect was there before the work was done which gave it legitimacy."

Defined Agreed Direction for Action: Stakeholders suggested that SSM "made us think and...we have taken a different approach...looking at what we've actually got in terms of the various initiatives...the common goal." The common purpose of the Partnership was strengthened and the action needed to take the IM\&T strategy forward was agreed.

Established a Business Case: As a direct result of SSM modelling work, the Partnership had a more robust profile, which added credibility to the IM\&T strategy. A business case was produced and used to justify an advertisement for an executive post to lead the IM\&T strategy.

\subsection{Contextual Factors Inhibiting Organizational Change Process}

The interviews identified a number of factors which were not caused by or connected to SSM, but which were considered to be influential in some way in the process of change and in the context in which SSM was applied. There were seven sub-categories, all of which could be said to be directly connected to organizational factors which were beyond the control of the SSM analysis.

Persistent Silo Culture: Several stakeholders commented that "some people are still in their silos", however, Stakeholder 9 suggested that there has been recognition that "We're all trying to reach something that's very similar...there's quite a lot of common ground." Yet, there was also a lack of communication and co-ordination as "people beaver away not realising that down the corridors, somebody else is beavering away on something probably very, very similar."

Espoused Partnership Culture: The belief in a culture of Partnership was often declared by stakeholders but the competition for resources remained. Stakeholder 12 referred to the mistrustful ethos rooted in a resource-led culture where "you don't want to tell people what you're actually planning or thinking in case they run off and get the money."

Tenacious Political Culture: One of the ways that political imperatives were manifested was in the reaction of some staff to the creation of the post of Executive Lead of the IM\&T strategy. This role would carry status and power and there appeared to be some "jockeying for position" amongst staff who were interested in applying for it.

Organizational History: The MBC had a history of being unable to move forward and implement the strategies it had formulated. Stakeholder 12 gave an example of "a strategy document that was produced five years ago" of which "not one of the actions had been implemented."

Strategic Events: There was substantial strategic change taking place across the MBC. For example, the introduction of Primary Care Trusts had been "a terrific distraction" for the Health Authority, constraining their participation in the SSM process. "Some of these people may not have jobs, so they are retreating back a bit to protect what they can."

Different Priorities: Those who felt themselves to be on the periphery of the Partnership articulated a focus on the survival of their own organizations. For example, Stakeholder 3 indicated that local priorities were more compelling, in terms of commitment: "can't give (the IM\&T strategy) the time, because our organization has a separate agenda... the inter-collaboration things are not given the time to do it, nor do you get thanks for it."

Lack of Momentum: Once the SSM models had been produced and the facilitator had left the organization, the momentum for the IM\&T strategy appeared to be lost. Stakeholder 15 explained, 
"Whilst it was quite important on the day, people moved quite quickly away from it." In contrast Stakeholder 12 believed that the SSM application had exerted a positive impact as "the logjam that was there which prevented any real change and real things happening, seems to have been swept aside."

\subsection{Factors Influencing the SSM Application}

The interviews also identified seven factors that appear to have inhibited open and candid participation in the SSM analysis, such as the presence of powerful managers and Chief Executives in the stakeholder group. The contribution of such senior personnel was, however, disputed; one stakeholder mentioned that the presence of such people gave the SSM work importance.

Timing of SSM Application: The SSM application occurred in parallel with wider discussion on how to move the stalled IM\&T strategy forward and the SSM workshop may have served to "unblock" this situation. The precise timing of the SSM analysis emerged as being significant as there was "a lot going on about shared services in [the $\mathrm{MBC}$ ]" forming "a momentum of change."

Understanding of SSM: Differences in the level of understanding of SSM were reported. Not all participants understood the holistic nature of the methodology, for example, regarding the language of SSM as "inhibiting" and that "there wasn't enough common ground such that we all agreed... I'd much rather just go back down to the requirements sort of model" (Stakeholder 1). Other stakeholders found the process a "utilitarian way of working... that is very flexible" (Stakeholder 6).

Potential Intimidation: No one claimed that they themselves were inhibited by the status of hierarchically powerful managers and their presence in the SSM process, but reference was made "to the unequal power in the debate." This was acknowledged by one of the Chief Executives as "It's to do with how vocal people are... We're confident and it does make it difficult for other people to participate." Unequal Status and Power: The unequal influence of powerful agents in the process was underscored by references to the importance of status in the organization: "Someone in this borough has got quite a high-paid job... and their job title altered recently, simply because their title... was perceived as lowstatus." However, Stakeholder 6 felt although they were "probably the least senior person" in the SSM workshop, they felt treated on their "ideas, thoughts and abilities and not any perceived status." Hidden Agenda: References was made to senior staff being "major distorters", for example, Stakeholder 15 thought that the political culture of "jockeying" to lead the IMT\&T strategy had influenced the intervention of some stakeholders during the SSM analysis stage, "some people have got their eyes on the job...and (were) also wanting to influence the person specification and the job description."

Facilitator Intervention: Stakeholders regarded the facilitator and her interventions as fulfilling a number of roles: as "expert on the methodology", guide in the application of the methodology; and help when "we were getting a bit lost... and you [the facilitator]...kind-of kick started it again" (Stakeholder 5). One stakeholder thought that the facilitator influenced the change process and that the facilitation process was "very powerful." The difficulty of a "clear dividing, line between... process and content" was also highlighted.

Neutrality of Facilitation: The neutrality of the facilitator was regarded as important by several stakeholders; "Anybody who tried to do it...from within the organization has got baggage... external objective facilitation role tied up with the methodology was absolutely crucial" (Stakeholder 16). However, Stakeholder 7 suggested that "When (colleague X) came...it was quite clear that, you might well think that you see yourself as neutral but his interjection would question that."

\section{$6 \quad$ Phase 4: Post SSM Application Evaluation (12 Months)}

The following categories emerged from the semi-structured interviews carried out 12 months after the SSM application was complete, shown in Table 2. 


\subsection{Contribution of SSM Activity to Organizational Change Process}

It was evident during these interviews that there had been what could be described as an attitudinal shift within the problem environment towards a more tangible partnership ethos, though the degree of shift was perceived as small. The partnership still did not have an effective IM\&T strategy and SSM had not, in the perception of many of the stakeholders, contributed significantly to any such shift. Comments regarding contribution of SSM focussed on three factors.

Created Organizational Insight: The SSM modelling work had shown that the strategic direction had to be resolved before the IM\&T strategy itself could be developed. Yet, it appears that the group had reverted back to grappling with the technical problems once the SSM application had ended.

Facilitated Move Towards Partnership Culture: Most stakeholders felt that the MBC had perhaps moved closer to a genuine partnership culture, "a culture where people are mindful that we are trying to work together...there is a consciousness that there's more to be gained by working together." (Stakeholder 13).

Contribution of SSM Difficult to Quantify: Whilst acknowledging that SSM had contributed to a sense of change within the partnership, stakeholders found this contribution difficult to quantify. Stakeholder 12 explained 'I don't think it's possible to attribute it to one thing because life isn't like that" however, "up to that point [the SSM activity] everybody was all over the place...Now, we're all marching behind the same things, so something has changed."

\subsection{Contextual Factors Inhibiting Organizational Change}

The initial interviews had raised factors that were not caused by or connected to SSM, but were considered to be influential to the process of change. In the second round of interviews they constituted a much larger part of the narrative of concerns articulated, suggesting potential reasons for the lack of momentum.

Persistent Silo Culture: SSM "got people thinking differently" and provided the opportunity "to break out of the silos" but there had been a return to silo working. Stakeholder 13 reported that "we still have silos, and some of them are new silos, actually."

Espoused Partnership Culture: Although "there's a lot of excellent lip service paid to it [partnership working]" issues of "resources", "budgets" and different "priorities" remain. Stakeholder 15 explained that "how we turn partnership into real operational outputs" has not been addressed.

Tenacious Political Culture: The impact of the political culture on the ability of the Partnership to make any further progress towards an IM\&T strategy was referred to, either directly or indirectly, by most of the stakeholders. The competitive and macho culture of the MBC, one of the consequences of which was a jockeying for the position to lead the IM\&T strategy, referred to in the initial interviews, had halted the appointment process. It was suggested that "people see opportunities in things, especially if they're part of developing them. They get attached and they can muddy the waters."

Strategic Events: Substantial changes concerning the Primary Care Trusts were still ongoing and there was a merger between three health services. Some stakeholders had visited a comparable situation in Scandinavia, earlier in the year. From this visit Stakeholder 14 concluded that there was a need to "create a structure in which you have to hold the IM\&T [strategy]." This was also reached as an outcome of the SSM application, yet it was presented as a fresh insight from the Scandinavian experience. This "helped us to see...not only what was necessary but how it could actually be done in practice and that's helped raise the awareness and the profile and the level of commitment."

Different Priorities: The Partnership struggled as "Where people have got to make choices about putting time into partnership working or into delivering and managing their own internal organization's demands, nearly all of it's going to internal demands." 
Lack of Momentum: Although "everyone agrees that it [the SSM activity] was a very good approach" the work begun during the application needed to be continued. Several stakeholders held the view that "there has been nobody pulling people together to get together to actually use the methodology...it sowed a seed and that it needed some continuation and some nurturing." Stakeholder 10 suggested that "..had we had the resolve and made the investment...it [SSM] would have had a directly traceable impact.. We just lost the plot."

Lack of Ownership: Several stakeholders referred to a lack of "a full-time resource to push this [IM\&T strategy] forward." There was no "champion or... a designated lead officer whose job it is to lead that strategy." Stakeholders made the point that "all of us were busy" and "It's not our job".

Lack of Resources: Finance hindered the appointment of an executive to lead the IM\&T strategy, "The money we were prepared to pay wasn't going to get you a (names colleague) sort of person." Change of Personnel: Over the year there had been changes in personnel, which had then appeared to shift the structure of power at a senior level; "the core group who met and...went through the SSM stuff really hadn't been able to influence direction with the [new] main players."

Lack of Alignment of Strategy and Processes: Stakeholder 5 agreed "there was a lot of coming together and mutual understanding" but "practically, on the ground not much has changed." One stakeholder suggested there was a widespread belief that the IM\&T strategy was not a priority and not sufficiently grounded in the reality of the everyday concerns of the MBC, for example: "What's that [IM\&T strategy] going to deliver to so and so who doesn't have a council house... who's struggling to feed her kids... there are tremendous benefits in progressing this information society agenda ...but they're quite long-term and...the nature of politicians, they're always looking for quick wins."

\section{Discussion}

Analysis of the interviews revealed a causal connection between the ultimate effectiveness of SSM and the tenacity of the existing politics and culture of the problem context. The SSM application was seen by stakeholders as episodic, and although it may have contributed to a small attitudinal shift towards partnership working, other organizational factors also contributed to this shift. The immediate outcomes of the application were promising, and if the post of Executive Lead to the IM\&T strategy had been appointed it is likely that deep structure change could have been achieved which would have demonstrated a causal relationship to the SSM application. The failure of the appointment can be attributed, in large part, to organizational politics and the interplay of power and influence amongst stakeholders.

SSM gave stakeholders the creative space and confidence to share different views, a process of strengthening in the common purpose of the Partnership. This resonates with long-established theorizing on partnership working, which talks of a shift from organization to environment focus (Mackintosh, 1992). Additionally, some of the comments suggest that totally candid participation in SSM was not achieved and that there was, in fact, "unequal power" in the debate. In spite of the espoused willingness of stakeholders to engage in the non-hierarchical and egalitarian approach, it clearly carried less credibility as a strategy for real survival than the prevailing political culture. Further, the neutral role of the facilitator was also compromised by the prevailing political ethos. The SSM application, could not maintain political independence in the prevailing macho culture of the environment.

Power was manifest both within the SSM application process and in the wider structures that framed the case study context, where these preceded the application and shaped its implementation and subsequent fate. What is at issue here is the substantive capacity of SSM to address tenacious political cultures which appear to be inimical to the participative and non-hierarchical functioning of SSM. This is in spite of the will of many of the individuals in the problem situation to adopt such a participative approach, also manifest in their very selection of SSM as the approach of choice. The findings are discussed in 
four categories: the process of stakeholder selection; the structure of power underpinning the stakeholder analysis; the ensuing power structure within the problem situation; the role of SSM and systemic change.

\subsection{Stakeholder Selection}

Stakeholders are key in implementing change in public organizations (Steane et al., 2015). SSM models do not prescribe when or how the process of stakeholder selection is done, or who does it. The implication is that the selection of stakeholders is a negotiated process regarding whom should take part between the facilitator and client. White (2006) believes that the question of who is involved in problem structuring method applications and the reasons for this involvement are crucial. Shaw et al., (2006) consider that the widest possible selection of stakeholders in problem structuring method interventions is important. These arguments suggest a high degree of ephemerality and partiality in stakeholder selection. Given that stakeholder selection needs to be done at the beginning of the application, there is a likelihood that the facilitator may not know enough about the organization and client views may predominate in that selection process. Political and cultural factors may militate against a truly representative or otherwise appropriate stakeholder group. Data analysis from this study suggests that stakeholders can be problematic and be greatly influenced by cultural and political factors in the problem situation.

There is no formalized process for assembling or inserting the political and cultural knowledge of context within SSM's structures of problem-solving. Torlak and Müceldili (2014) suggest that a preliminary diagnosis is made at the start of the SSM application; this approach was adopted in phase 1; however, unless the facilitator is extremely politically astute, it seems inevitable that knowledge about cultural and political issues within the problem situation may to some degree be incomplete. In any case, making this knowledge overt or explicit may undermine the facilitator's role as a culturally independent agent and unleash potentially disruptive cognitions within the problem situation. The findings of this research indicate that the process of stakeholder or stakeholder selection in SSM must be informed fully by these issues in an attempt to mitigate the negative influences of organizational power in the ensuing analysis. In highly politicized environments, however, this may not actually be possible.

\subsection{Power Structure of the Stakeholder Group}

The Partnership as an organizational entity carried political weight and it became clear that some stakeholders attempted to use the SSM application to consolidate or achieve personal power and influence.

For example, during the application process, a number of stakeholders referred to a "jockeying for position". The political dominance of the "quick win" culture was such that it substantially countered the long term achievement of an information strategy, the SSM application appeared to have made very little impact on the existing power structure.

Flood and Jackson (1991) have contended that SSM is in practice managerialist, serves dominant (manager) groups, while worldviews reflect existing social inequalities. The case has demonstrated that Jackson's (1982) 'framework of domination', whereby powerful stakeholders are seen to drive the process, is an observable phenomenon in highly politicized situations. SSM was not transferred as a methodology and the single application was not sufficient to change organizational culture and politics. The SSM application appears to have become an instrument of political power in itself; it was captured by a dominant coalition of agents. This only served to distort its impact on the change process. It could be concluded that the egalitarian, participative and non-partisan requirements of SSM posed a challenge or threat to the environment. Given the evidence, it is equally possible that it may have been too weak to affect the tenacious political culture. These findings confirm Callo and Packham's (1999) observation to the effect that genuine debate is difficult to achieve in corporations with strong hierarchies of power. 


\subsection{Power Structure of Problem Domain}

The problem situation implied potential outcomes that were equally concerned with process and attitudinal change. The prevailing organizational culture was tenacious; this tenacity affected a host of process outcomes and also appeared to impede progress towards breaking down the traditional silos that blocked integrated working approaches. Silos form from different tribes of government workers in specialized functions, which should not be eliminated as the distinct culture, language and processes within a silo are needed by the specialism (Tett, 2015). However, silos can become entrenched when competing for resources (Tett, 2015). Ruijer and Huff (2016) propose a networks strategy to overcome the boundaries in bureaucratic organizations by overlaying horizontal openness across functional boundaries, to share information and facilitate collaboration. Creating cultural change requires new shared systems of meaning to be formed, accepted and internalized (Morgan, 2006). The formation of the Civic Partnership established a network to facilitate openness at a strategic level, however, there was a lack of shared meaning in the system of the partnership. Flood (1999:111) suggests that Checkland's SSM seeks to reach an accommodation of views, however, individual needs can re-emerge (Steane et al., 2015).

Tuan and Shaw (2016:56) suggest that participation in "systemic thinking promotes toleration". At the start of the case study the different stakeholders represented different partner organizations with disparate, polarized and fragmented viewpoints. Through the SSM workshop a way forward was agreed through an accommodation of the different views. When the stakeholders returned to their individual organizations the accommodation of viewpoints started to fragment within the tenacity of the silo culture, the pressures upon individual stakeholders and procedural uncertainty. Steane et al., (2015: 265) suggest that stakeholders may come to a temporary agreement, perhaps out of political necessity but there can be lack of substantive agreement; it is a "momentary convergence with provisional closure". Although there was some movement towards partnership working, the silo culture prevailed; there was a failure to "institutionalise a culture of openness" (Ruijer and Huff, 2016).

\subsection{SSM and Systemic Change}

The aim of this research has been to examine the effectiveness of SSM in the process of organizational change. This section examines the problems associated with establishing causal links between the SSM application and the organizational events taking place during, or subsequent to the analysis. Malinova et al., (2016:161) describe organizational change as emerging from organizational learning processes. In this case, there was a modest change in the organizational culture which may partly be attributed to the learning processes offered within SSM. Several stakeholders referred to the difficulty of attributing, a marginal movement towards a greater partnership culture to the use of SSM. This was because other events were also happening at the same time, which could have contributed to this cultural shift. There were also some stakeholders that did not perceive that any change had taken place.

Checkland refers to the flux and transformation of organizational life. Situations are continually changing and the behaviour of people within those situations undoubtedly contributes to this fluidity. SSM applications are capable of changing or transforming the belief systems of stakeholders, through the creation of insight, clarity and exposure to the logically expressed and interpretable worldviews of others. The results of the evaluation interviews demonstrate that use of the methodology had created insight and had enabled the problem situation to be perceived more clearly. It is possible that the organizational behaviour of some stakeholders changed as a consequence of this, although this change may not have been a radical one. It may have manifested itself only in a psychological or attitudinal change, which was not immediately obvious within the everyday working life of the organization.

These observations confirm Beeson and Davis (2000) central emphasis on the human element in their reading of soft approaches to systems analysis. Though change is constitutive of organizational life, its direction and terminus is not pre-figured, automatic or teleological. Instead, it involves processes of 
negotiation, invention, perception and participation. Similarly, the lack of tangible process outcomes may confirm Flood and Jackson's (1991) contention that the cultural feasibility of change is in fact bounded by conformance to the dominant culture and the dominant coalition (of power). Jackson (1982) also alludes to this in his claim that facilitators may be forced to abandon radical systems which do not reflect the social and cultural realities of the situation. Radical change could not be said to have been achieved. The express wish to move towards seamless, integrated working could be interpreted as a radical departure from the MBC's silo culture.

\section{Conclusion}

This case study has demonstrated that two fundamental, underlying principles of SSM cannot be assured. These are:

- That the open and candid participation of stakeholders cannot be assumed, nor evaluated, and

- The absolute neutrality of the facilitator is compromised by the methodology itself, which requires active facilitator involvement and cultural and political knowledge.

Section 5.3 refers to some of the factors affecting stakeholder engagement. Additionally, the facilitator observed the dynamic between herself and participants throughout the application. It is perhaps not surprising that it was observed that the physical presence of the facilitator helps to mitigate the consequences of inconsistent levels of understanding and participation noted above, and that this influence was lost somewhat when the facilitator left the organisation. Most importantly, participants' perceived SSM as a 'means to an end' (ie an approach which could help them to resolve the IM\&T issue), rather than an organisational modus operandi. In this sense, participants clearly did not regard SSM as a permanent feature in their organisational world.

The study has contributed to the wider understanding of the specific contributions of SSM to facilitate organizational change and highlighted contextual factors that can impede both participation in SSM activity and cultural change. Specifically, these factors may limit the capacity of SSM to address powerful political cultures, particularly where SSM is episodic. The principles of cultural change need to become institutionalized to drive organizational change reflected in an alignment between strategy and supporting processes.

A limitation of the study is that it is reliant on a single case in one country. The 16 stakeholders were at senior levels of their organizations, each representing an individual agency within the MBC; their views may not have been shared by others in their organizations. Further studies are needed to determine the extent to which the factors influencing and inhibiting the role of SSM in organizational change are exhibited in other organizations, and to seek ways to strengthen the capability of SSM to affect change in dominant organizational cultures. Yet, the overarching contentions remain: that SSM is an attractive method for addressing inchoate problems. Its functioning in practice needs to be strengthened by greater understanding of the strength of the political organizational context and an awareness of its influence on the sanctity of the SSM activity.

\section{References}

Beeson, I. A. and Davis, C. (2000). "Emergence and Accomplishment in Organisational Change." Journal of Organisational Change, 13(2), 178-189.

Callo, V. N. and Packham, R. G. (1999). "The Use of Soft Systems Methodology in Emancipatory Development." Systems Research and Behavioural Science, 16(4), 311-319.

Checkland, P. \& Holwell, S. (1998). Information, Systems, and Information Systems. Chichester: Wiley.

Checkland, P. (1981). Soft Systems Methodology in Action. Chichester: Wiley.

Checkland, P. and Scholes, J. (1999). Soft Systems Methodology in Action. Chichester: Wiley. 
Connell, N. A. (2001). "Evaluating Soft OR: some reflections on an apparently 'unsuccessful' implementation using a Soft Systems Methodology (SSM) based approach." Journal of the Operational Research Society, 52(2), 150-160.

Crabtree, F. and Miller, W. L. (1999). Doing Qualitative Research. 2nd Edition. London: Sage Publications.

Dowling, B., Powell, M. and Glendinning, C. (2004). "Conceptualising Successful Partnerships." Health and Social Care in the Community, 12(4), 309-317.

Flood, R. L. and Jackson, M. C. (1991). Creative Problem Solving: Total Systems Intervention. Chichester: Wiley.

Glaser, B. and Strauss, A. L. (1967). The Discovery of Grounded Theory. New York: Aldine.

Jacobs, B. (2004). "Using Soft Systems Methodology for Performance Improvement and Organisational Change in the English National Health Service." Journal of Contingencies and Crisis Management, 12(4), 138-149.

Jackson, M. (1982). "The Nature of Soft Systems Thinking: the work of Churchman, Ackoff, and Checkland." Journal of Applied Systems Analysis, 9, 17-27.

Kalim, K., Carson, E. and Cramp, D. (2004). "The Role of Soft Systems Methodology in Healthcare Policy Provision and Decision Support." In: Proceedings of the IEEE International Conference on Systems, Management and Cybernetics, 6, 5025-5030.

Kelliher, C. and Parry, E. (2015). "Change in Healthcare: the Impact on NHS Managers", Journal of Organizational Change Management, 28(4), 591-602.

King, N. (1998). "Template Analysis". In: Symon, G. \& Cassell, C. (eds.) (1998). Qualitative Methods and Analysis in Organisational Research: a Practical Guide. London: Sage Publications, 118-134. Knight, L. \& Harland, C. (2005). "Managing Supply Networks: organisational roles in network management." European Management Journal, 23(3), 281-292.

Kotiadis, K. (2007). "Using Soft Systems Methodology to Determine the Simulation Study Objectives." Journal of Simulation, 1(3), 215-222.

Kuipers, B. S., Higgs, M., Kickert, W., Tummers, L., Grandia, J. and Van der Voet, J. (2014). "The Management of Change in Public Organizations: a Literature Review". Public Administration, 92(1), 1-20.

Lee, G. \& Kwak, Y. H. (2012). “An Open Government Maturity Model for Social Media-Based Public Engagement". Government Information Quarterly, 29(4), 492-503.

Mackintosh, M. (1992). "Partnership: issues of policy and negotiation." Local Economy, 7(3), 210224.

Malinova, L., Bednar, P. M. and Welch, C. (2016). "Facilitating Organizational Change: a Collaborative, Open Systems Perspective." In: Benson, V. and Filippaios, F. (Eds.), Proceedings of the $15^{\text {th }}$ European Conference on Research Methodology for Business and Management Studies, 910 June, 2016, London, UK, 159-166.

Morgan, G. M. (2006). Images of Organizations. London: Sage Publications.

Ruijer, E. H. J. M. and Huff, R. F. (2016). "Breaking Through Barriers: the impact of organizational culture on open government reform." Transforming Government: People, Process and Policy, 10(2), 335-350.

Shaw, D., Edwards, J. S. and Collier, P. M. (2006). "Quid Pro Quo: reflections on the value of problem structuring group workshops." Journal of the Operational Research Society, 57, 939-949.

Signoretta. P. \& Craglia, M. (2002). "Joined-up Government in Practice: a case study of children's needs in Sheffield." Local Government Studies, 28(1), 59-76.

Steane, P., Dufour, Y. and Gates, D. (2015). "Assessing Impediments to NPM Change." Journal of Organizational Change Management, 28(2), 263-270.

Stowell, F. (ed.) (1995). Information Systems Provision: the Contribution of Soft Systems Methodology. London: McGraw-Hill.

Strauss, A. \& Corbin, J. (1998). Basics of Qualitative Research: Techniques and Procedures for Developing Grounded Theory. London: Sage Publications. 
Tett, G. (2015). The Silo Effect: The Peril of Expertise and the Promise of Breaking Down Barriers. London: Simon and Schuster.

Torlak, N. G. and Müceldili, B. (2014). "Soft Systems Methodology in Action: the example of a private hospital." Systemic Practice and Action Research, 27(4), 325-361.

Tuan, N-T. and Shaw, C. (2016). "Consideration of Ethics in Systemic Thinking." Systemic Practice and Action Research, 29(1), 51-60.

Wastell, D., Kawalek, P., Longmead-Jones, P. and Ormerod, R. (2004). "Information Systems and Partnership in Multi-agency Networks: an action research project in crime reduction." Information and Organisation, 14(3), 189-210.

Weber, R. P. (1985). Basic Content Analysis. London: Sage Publications.

White, L. (2006). "Evaluating Problem Structuring Methods: developing an approach to show the value and effectiveness of PSMs." Journal of the Operational Research Society, 57, 842-855.

Wilson, B. (1990). Systems Concepts, Methodologies and Applications. Chichester: Wiley.

Wilson, B. (2001). Soft Systems Methodology: conceptual model building and its contribution. Chichester: Wiley. 